\title{
The Effect of Epinephrine on Immunoreactive Insulin Levels in $\operatorname{Man} *$
}

\author{
Daniel Porte, Jr., $\dagger$ Alan L. Graber, Takeshi Kuzuya, $\$$ and \\ ROBERT H. Williams $\S$ \\ (From the University of Washington Department of Medicine, Seattle, Wash.)
}

The mechanisms by which epinephrine elevates the blood sugar have been of considerable interest for more than 25 years. In an extensive review in 1956, Ellis suggested that the two major influences on glucose metabolism were increased glycogenolysis in the liver and peripheral tissues, and direct inhibition of glucose uptake by muscle (1). There is, however, the additional possibility that epinephrine might decrease insulin levels. The introduction of insulin immunoassay $(2,3)$ has allowed us to examine this third hypothesis in man. Our data show that epinephrine infusion is not associated with a rise in serum immunoreactive insulin (IRI) despite significant hyperglycemia. In addition, epinephrine was found to inhibit the expected rise in IRI after administration of exogenous glucose, glucagon, and tolbutamide.

\section{Methods}

Volunteers selected were apparently normal, ambulatory, nonhospitalized, nonobese, young adult men and women. There were 13 men of ages 21 to 29 , weight range 61 to $95 \mathrm{~kg}$, and height 148 to $197 \mathrm{~cm}$, and 6 women, of ages 21 to 31 , weight range 51 to $65 \mathrm{~kg}$, and height 160 to $179 \mathrm{~cm}$. None had any history of major

* Submitted for publication July 19, 1965; accepted November 2, 1965.

Supported in part by grants AM-02456 and T1-AM5020 from the National Institute of Arthritis and Metabolic Diseases. A portion of this work was conducted through the Clinical Research Center facility of the University of Washington (National Institutes of Health grant FR-37).

Presented in part before the American Society for Clinical Investigation, May 3, 1965, Atlantic City, N. J.

$\dagger$ This work was carried out during the tenure of an Advanced Research Fellowship of the American Heart Association and supported in part by the Idaho Heart Association.

$\ddagger$ Present address: Third Department of Internal Medicine, University of Tokyo, Hongo, Tokyo, Japan.

$\S$ Address requests for reprints to Dr. Robert $\mathrm{H}$. Williams, Dept. of Medicine, University of Washington, Seattle, Wash. 98105. medical illness. None had any close relative who was known to be diabetic. All were within $15 \%$ of their ideal body weight. ${ }^{1}$ Approximately $20 \%$ had been previously tested at random with the $100-\mathrm{g}$ oral glucose tolerance test and were normal by the criteria of Mosenthal and Barry (4). All had fasting plasma glucose less than $105 \mathrm{mg}$ per $100 \mathrm{ml}$. For the study, no solid food was taken after the previous evening meal at 6 to 7 p.m., and no liquids except water were taken after midnight. No smoking was allowed on the day of the test. Upon arriving at the Clinical Research Center for study the volunteer was put to bed, and a slow intravenous $0.85 \%$ $\mathrm{NaCl}$ drip was begun through each of two indwelling venous plastic catheters. Blood samples were taken through one catheter, and drugs or glucose was infused through the other with a constant drive syringe infusion pump. No anticoagulants were given to the patient or were present in the sampling syringe.

Blood samples were obtained every 15 minutes and sampled for measurements of glucose, IRI, free fatty acids (FFA), and glycerol. Blood for insulin assay was allowed to clot for 1 hour at room temperature, and the serum was frozen at $-19^{\circ} \mathrm{C}$ until analyzed by the double antibody immunoprecipitation technique (5). Neither epinephrine ( $1 \mu \mathrm{g}$ per $\mathrm{ml}$ ) nor tolbutamide (50 $\mathrm{mg}$ per $\mathrm{ml}$ ) had any measurable effects when added to the immunoassay system in vitro. The glucagon preparation assayed 5 to $7 \mu \mathrm{U}$ of immunoreactive insulin per microgram of glucagon. This amount of insulin was considered to have no significant effect upon serum IRI with the infusion rate of glucagon used ( $5 \mu \mathrm{g}$ per minute). The human insulin standard was supplied.2 Blood samples for FFA, glucose, and glycerol were anticoagulated with heparin and kept chilled at $4^{\circ} \mathrm{C}$. The plasma was separated by centrifugation in the cold and frozen at $-19^{\circ} \mathrm{C}$ for future analysis. FFA were titrated against standard base by a modified Dole procedure (6). Plasma glucose was measured by a Technicon autoanalyzer with a ferricyanide reagent. Glycerol was measured by the enzymatic method of Wieland (7) with commercially available glycerokinase and glycerophosphate dehydrogenase. ${ }^{3}$

1 As calculated from statistical tables of the Metropolitan Life Insurance Co.

2 Lot no. 10-1862, $24 \mathrm{U}$ per mg, supplied by courtesy of Dr. J. Schlichtkrull, Novo Therapeutic Laboratories, Copenhagen.

${ }^{3}$ C. F. Boehringer and Sons, Mannheim, Germany. 


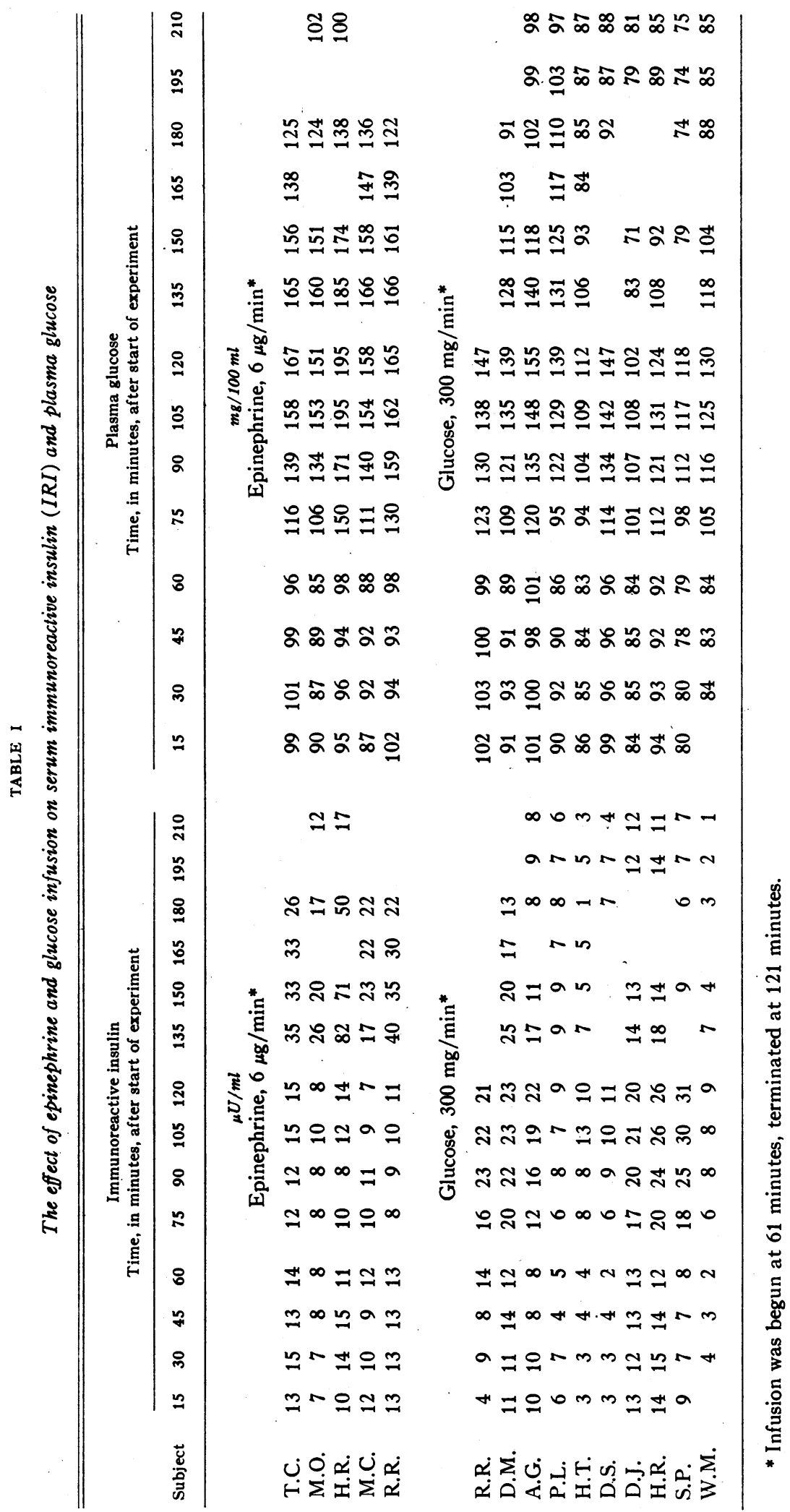




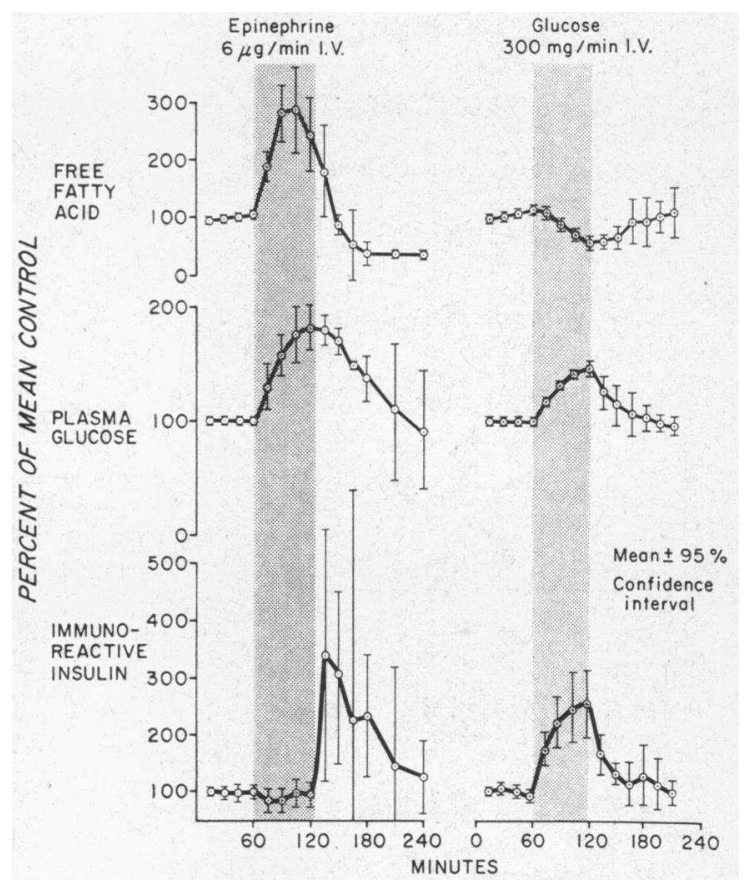

Fig. 1. A COMPARISON OF THE EFFECTS OF EPINEPHRINE AND GLUCOSE. Five subjects were given epinephrine; 10 subjects were given glucose. Each pair of brackets represents the $95 \%$ confidence limit of the mean value. Brackets that do not overlap are significant at least at the $\mathrm{p}<0.05$ level. For each study the mean of four control samples taken during the first hour is set at $100 \%$, and all values are compared with this mean control value.

All drugs given to the subjects were commercially available and included tolbutamide, $1 \mathrm{~g}$ per $20 \mathrm{ml} ;{ }^{4}$ glucagon, $1 \mathrm{mg}$ per $\mathrm{ml}^{5}{ }^{5}$ and epinephrine, 1,000 $\mu \mathrm{g}$ per ml. ${ }^{6}$ When epinephrine was infused, it was protected against oxidation by ascorbic acid ( $2.5 \mathrm{mg}$ per $\mathrm{ml}$ of solution).

\section{Results}

The infusion of epinephrine, $6 \mu \mathrm{g}$ per minute, for 1 hour in five subjects resulted in a rise in plasma glucose to a mean of $168 \mathrm{mg}$ per $100 \mathrm{ml}$, or $180 \%$ above the basal level. Despite this rise in glucose, serum IRI remained unchanged until after the infusion was stopped. Within 15 minutes of stopping the epinephrine infusion, serum IRI increased to a mean of $41 \mu \mathrm{U}$ per $\mathrm{ml}$ from a mean basal level of $12 \mu \mathrm{U}$ per ml (Table I, Figure 1). This rapid rise was maximal between 15 and 30

4 Upjohn, Kalamazoo, Mich.

5 Crystalline glucagon, Eli Lilly Co., Indianapolis, Ind.

6 Parke, Davis \& Co., Detroit, Mich. minutes. In a few selected patients the serum IRI was always lower at 5 or 10 minutes than at 15 minutes after epinephrine was stopped. This IRI response was compared to that obtained in 10 subjects with an infusion of glucose ( $300 \mathrm{mg}$ per minute) in an attempt to duplicate the plasma glucose values found with epinephrine. Although the mean plasma glucose in these 10 subjects was lower at the end of a 1-hour glucose infusion than at the end of the epinephrine infusion, there was a significant $(p<0.05)$ rise in mean serum IRI for all four samples taken during the glucose infusion. This increase progressed to a maximum of $250 \%$ above a mean control IRI of $7.8 \mu \mathrm{U}$ per $\mathrm{ml}$ ( Table I). By inspection of Figure 1 it can be seen that the mean IRI values during glucose infusion are all significantly different from those during epinephrine infusion. Thus, the hyperglycemia associated with an infusion of $6 \mu \mathrm{g}$ per minute of epinephrine should have been sufficient to cause a significant rise in serum IRI. Two other subjects given prolonged infusions of epinephrine (6 $\mu \mathrm{g}$ per minute) for 4 and 7.5 hours showed similar results. One of these is shown in Figure 2. Despite persistent hyperglycemia there was a minimal, if any, rise in IRI until the infusion was stopped, when the usual postepinephrine rebound was found. In these studies, FFA clearly reached an early peak and then declined during the infusion to basal levels despite the stable insulin values, whereas plasma glycerol remained elevated throughout the epinephrine infusion.

To determine the effect of epinephrine upon IRI when other means of elevating the plasma glucose

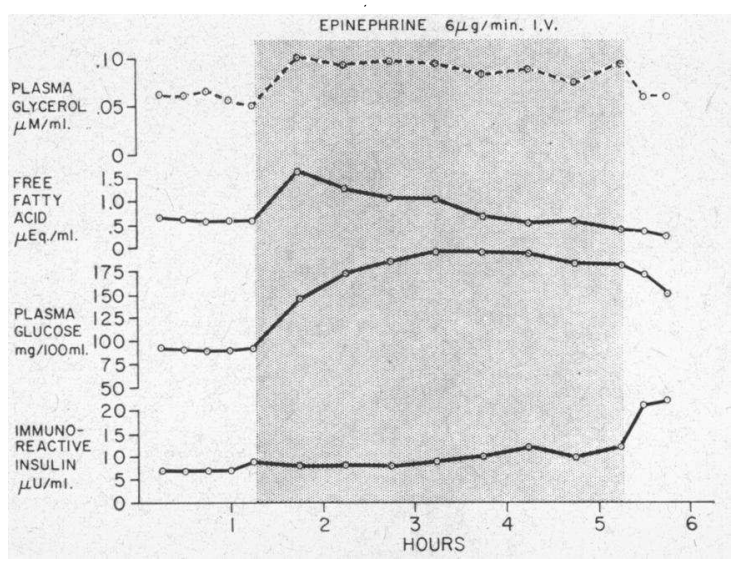

Fig. 2. The EFFeCt OF PROLONGEd INFUSION OF EPINEPHRine on Subject D.B. 
or stimulating insulin secretion were used, we administered glucagon and tolbutamide. Each compound was given to each subject both with and without simultaneous epinephrine infusion.

Glucagon, $5 \mu \mathrm{g}$ per minute, resulted in plasma glucose levels similar to those achieved with epinephrine, $6 \mu \mathrm{g}$ per minute, but somewhat higher than those obtained with glucose, $300 \mathrm{mg}$ per minute (Figure 3, Table II). In contrast to epinephrine infusion, the serum IRI was elevated during the glucagon infusion and declined after the infusion without a rebound. In contrast to glucose infusion, the serum IRI levels were much higher during the glucagon infusion, although both infusions were followed by a prompt return of IRI to basal levels. Despite the rapid decline in IRI after glucagon infusion each patient experienced a typical "hypoglycemic reaction" within 40 to 50 minutes. These reactions were characterized by subjective symptoms of nervousness and apprehension and accompanied by increased perspiration and tachycardia. They were coincident with the lowest plasma glucose and were followed by a prompt rise in plasma glucose and FFA (Figure 3 , Table II). This type of reaction was not found after glucose or epinephrine infusions. When

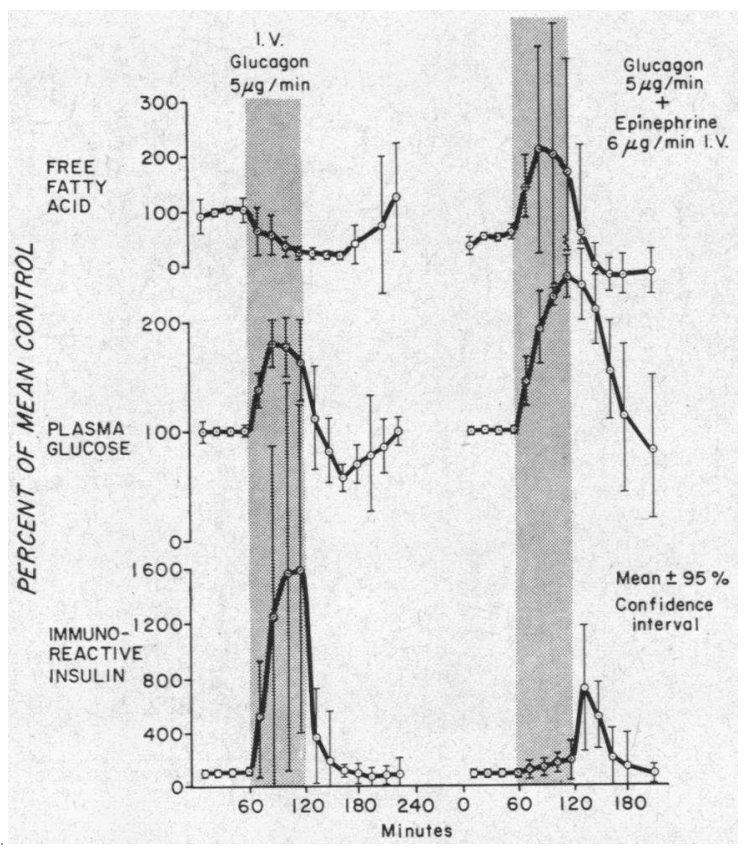

Fig. 3. A comparison OF GLUCAGON INFUSION With GLUCAGON AND EPINEPHRINE INFUSION. The same four subjects were given both infusions. See Figure 1.

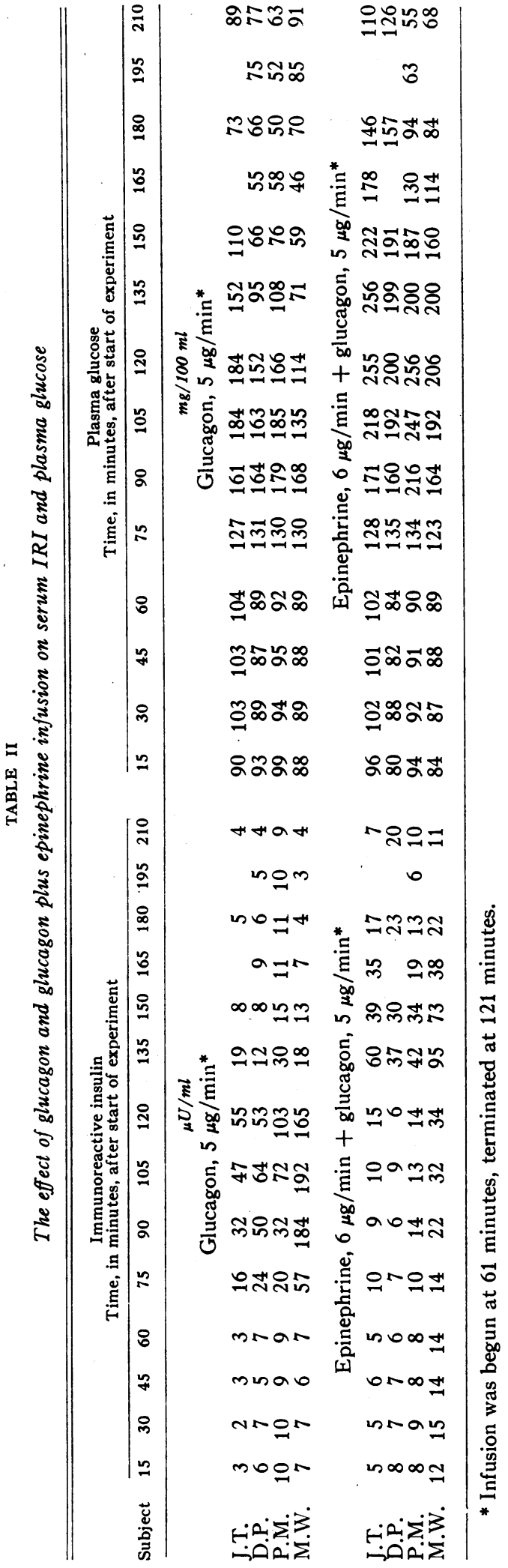




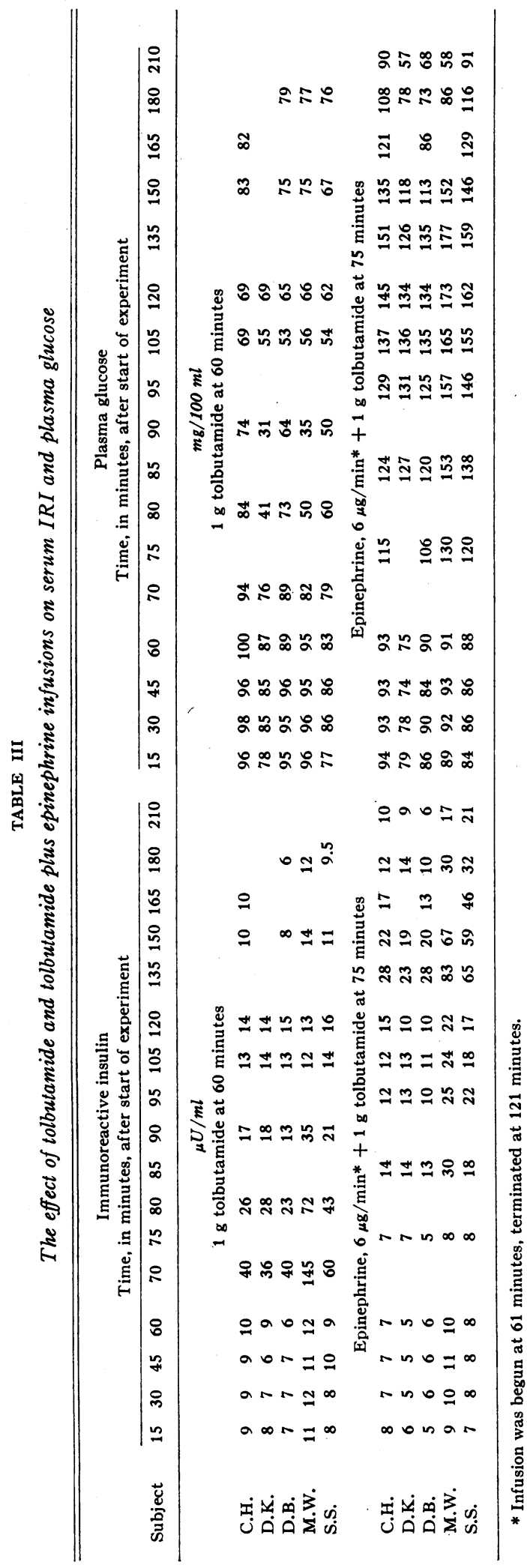

glucagon, $5 \mu \mathrm{g}$ per minute, and epinephrine, $6 \mu \mathrm{g}$ per minute, were infused simultaneously into the same four subjects, the serum IRI response was significantly less during the infusion $(\mathrm{p}<0.05$ by paired comparisons for all four samples). When the infusion was stopped, the serum IRI levels rose in a pattern similar to that when epinephrine was given alone, and they were significantly higher than after a 1-hour glucagon infusion (Figure 3, Table III).

In an analogous fashion sodium tolbutamide, 1 $\mathrm{g}$ in a single iv injection, was given to five subjects on 2 different days. On 1 day epinephrine, $6 \mu \mathrm{g}$ per minute, was infused for 15 minutes before and 45 minutes after tolbutamide, whereas on the other day tolbutamide alone was given. The insulin response was significantly diminished by the epinephrine $(p<0.05$ for the 10 and 20 minute post-tolbutamide samples), and the usual pattern of rebound of IRI after termination of the epinephrine infusion was observed (Figure 4, Table III).

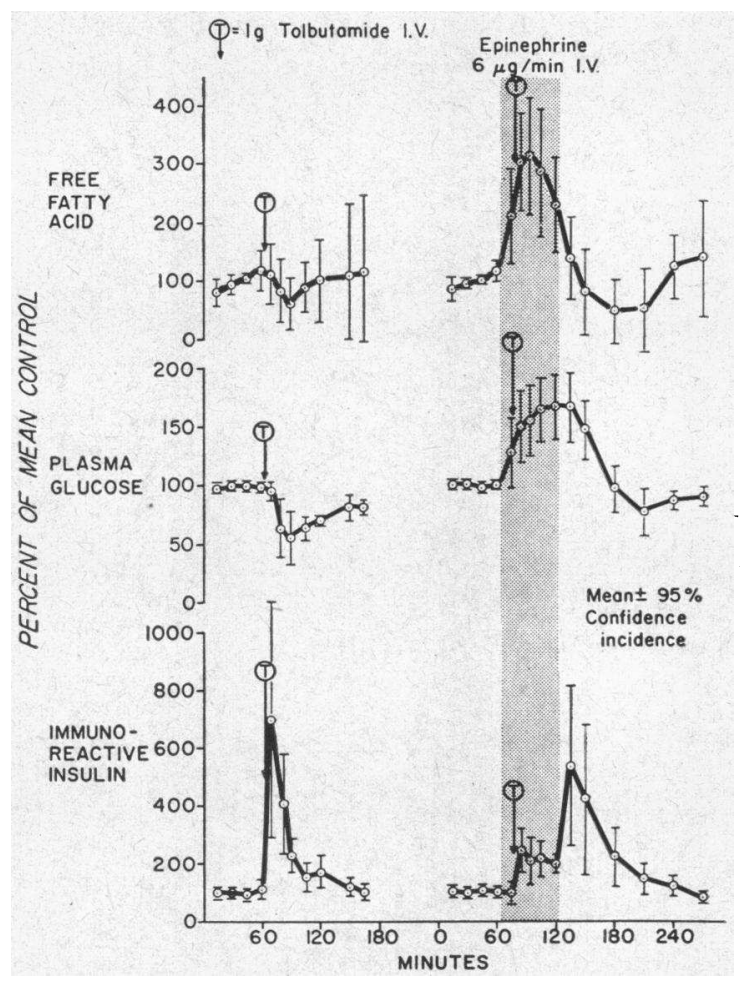

Fig. 4. A COMPARISON OF THE EFFECTS OF 1 G OF TOLBUTAMIDE GIVEN ALONE OR DURING AN EPINEPHRINE INFUSION. The same four subjects were tested twice. See Figure 1. 
An attempt was then made to compare the effect of exogenous glucose upon the IRI response. This study was complicated by the much higher glucose levels when glucose, $300 \mathrm{mg}$ per minute, and epinephrine, $6 \mu \mathrm{g}$ per minute, were infused simultaneously into four different subjects. Complete inhibition of insulin rise was noted during the infusions in two subjects, but only partial inhibition was observed in the other two (Figure 5, Table IV). The partial inhibition was suggested by the observation that all subjects showed a large rebound of serum.IRI after the infusions were stopped, with a peak between 15 and 30 minutes. In these latter studies, when both substances were infused, glycerol was measured to help distinguish between a fall in FFA caused by decreased lipolysis (decreasing glycerol) and that caused by increased uptake, re-esterification of FFA (stable or elevated glycerol), or both. This is based on the evidence that insulin lowers plasma glycerol, reflecting a direct inhibition of adipose tissue lipolysis (8-10). In the two individuals (D.K., M.O.) who showed no IRI rise during the combined infusions, there was a relative plateau of

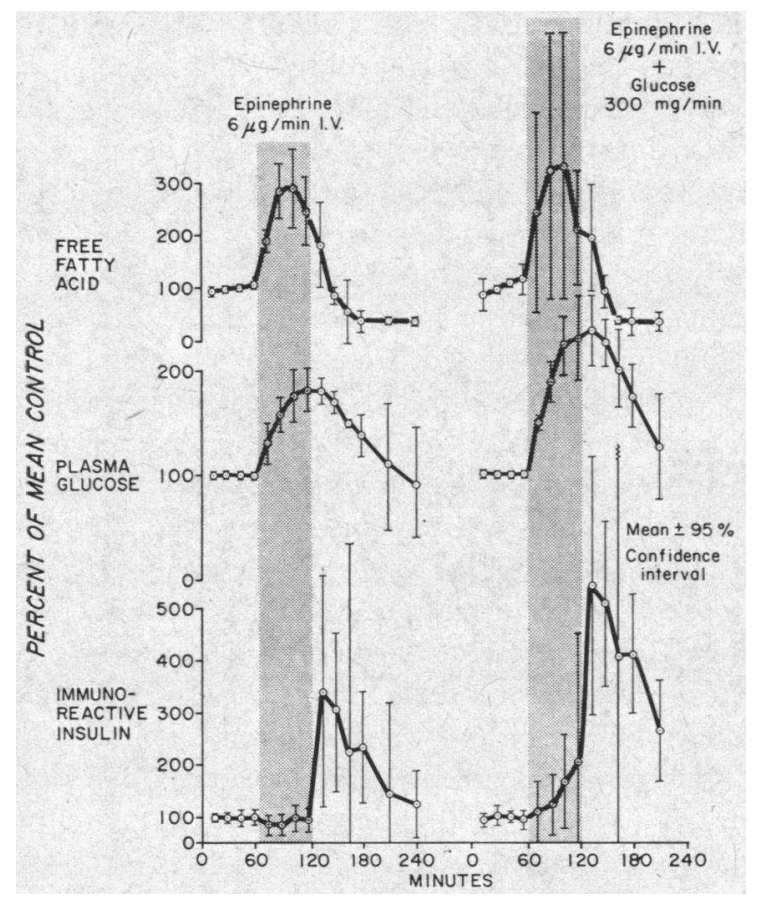

Fig. 5. A COMPARISON OF THE EFFECT OF EPINEPHRINE WITH EPINEPHRINE AND GLUCOSE INFUSION. Five subjects were given epinephrine; four different subjects were given both infusions. See Figure 1 .

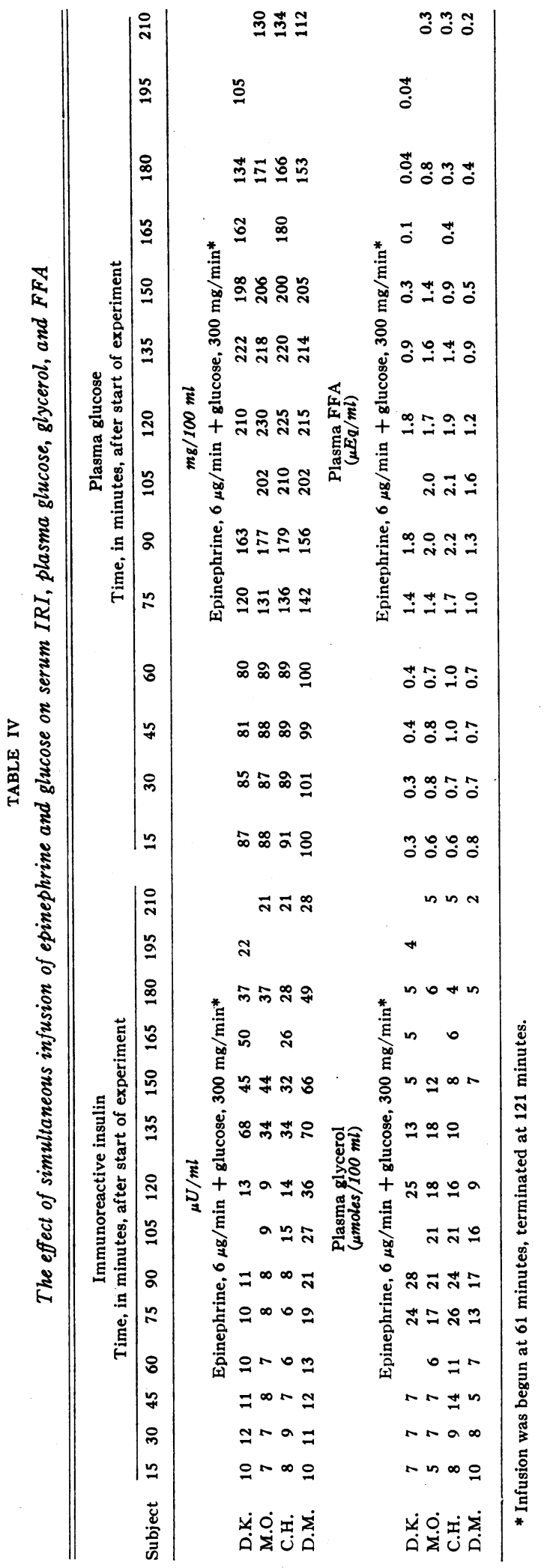




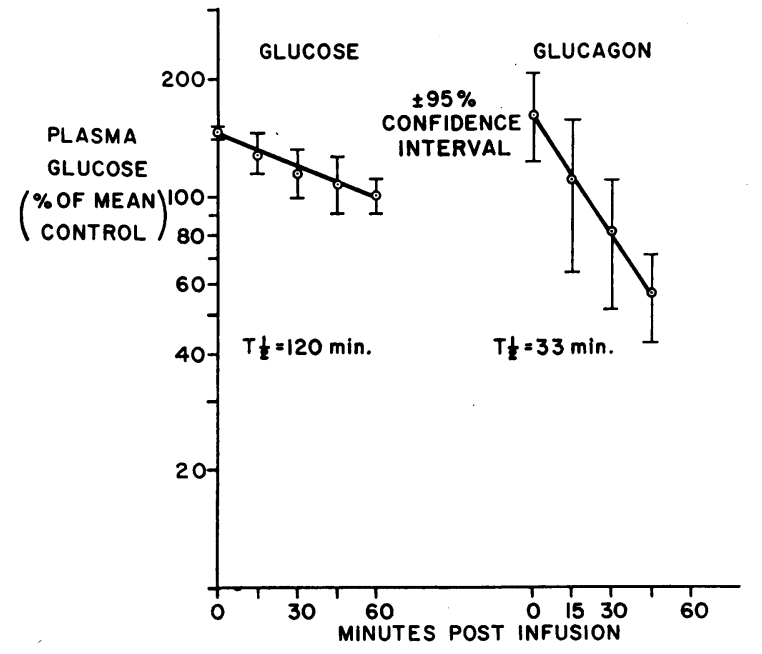

Fig. 6. A comparison of the MEAN Rate of Fall of THE PLASMA GLUCOSE AFTER A GLUCAGON INFUSION WITH THE RATE OF FALL AFTER A GLUCOSE INFUSION. $t_{1}=$ halftime.

plasma glycerol, whereas in the two subjects with a modest but definite rise in IRI during the combined infusions (C.H., D.M.) there was an early rise and then a decrease of about $50 \%$ in glycerol levels by the end of 1 hour, despite the continuing infusion of epinephrine (Table II).

\section{Discussion}

Epinephrine administration was associated with stable basal insulin levels despite hyperglycemia when given alone, and it inhibited the usual increases in serum IRI produced by exogenous glucose, glucagon, and tolbutamide. Those subjects with the greatest insulin responses to tolbutamide, glucose, or glucagon alone tended to be the same subjects in whom a partial response was still observed when such compounds were infused simultaneously with epinephrine. This indicates that the inhibition can be partially overcome by a sufficiently strong stimulus. Because of the variability in the magnitude of insulin responses in different subjects to any specific stimulus tested, a high degree of statistical significance was not always found in these studies. Therefore, caution must be exercised in the quantitative interpretation of results from one study. However, considered together, the pattern of responses was always the same when epinephrine was given, i.e., there was always a lesser increase in the IRI level during the insulinogenic stimulus plus epinephrine infusion than was observed for the insulinogenic stimulus alone. Furthermore, a rapid postinfusion increase in IRI occurred in every experiment in which epinephrine was used either alone or with other compounds. This constant pattern, although not susceptible to statistical analysis, tends to reinforce the conclusion that epinephrine does indeed prevent or diminish an insulin response. The magnitude of the rebound after epinephrine was variable but appeared to be greater in those subjects with larger IRI responses to glucose, glucagon, or tolbutamide alone. The variation in individual response was not related to obesity (11) since none of the patients was obese, nor was it found to correlate well with sex, body surface area, height, or weight. No measurements of plasma epinephrine levels were made, and it is possible these might have correlated better with the degree of epinephrine inhibition. Such variations in the magnitude of a normal IRI response make it difficult to delineate a quantitatively pathologic response without a much larger experience with apparently normal population groups. However, the glucagon study was unusual in several respects. The IRI levels were higher than observed with glucose alone, all values for IRI during glucagon infusion were higher, and the 1 -hour value was statistically different at the $\mathrm{p}<0.05$ level; more striking was the observation that each infusion was followed by clinically obvious hypoglycemia. This late hypoglycemic phase after glucagon infusion has been observed by others (12, 13) and, together with our IRI data, suggests that glucagon may raise insulin levels by some mechanism in addition to its hyperglycemic effects. Such an inference is supported by noting the rate of fall of the blood sugar after these infusions were stopped. The higher insulin values during a glucagon infusion were followed by a faster rate of glucose disappearance, whereas the lower insulin values during a glucose infusion were followed by a slower rate of glucose disappearance [half-time $\left(t_{\frac{1}{2}}\right)=33$ minutes, glucagon; $t_{\frac{1}{2}}=120$ minutes, glucose; Figure 6]. These observations are consistent with the hypothesis that either more insulin is secreted or less insulin is degraded during a glucagon infusion than during a glucose infusion with comparable blood sugar levels. 
The more prolonged epinephrine infusions indicate that epinephrine's suppressive effect on IRI levels can be maintained for hours. In addition we noted, as have others $(14,15)$, that after an initial rise FFA levels decline during continuous epinephrine infusions. This fall in FFA was attributed to the effects of insulin and glucose to reesterify fatty acids in adipose tissue. The observation in our studies that glycerol levels remained elevated while FFA declined is consistent with low levels of insulin during epinephrine infusion, because it has been shown that raising insulin levels by exogenous insulin administration lowers glycerol levels $(8,10)$. If low insulin levels were present, declining FFA levels could still result from either increased re-esterification of FFA in adipose tissue by the high glucose levels alone, by increased peripheral uptake of FFA secondary to the cardiovascular effects of epinephrine, or by both.

The hypothesis that epinephrine inhibits the secretion of insulin was suggested as early as 1930 by Colwell and Bright (16) when they noted a low respiratory quotient during epinephrine infusions in cats. These early studies have been recently strengthened by studies in vivo in dogs, when pancreatic venous blood was biologically assayed for insulin after an epinephrine infusion (17), and by in vitro studies in rabbit pancreatic slices, when epinephrine was found to prevent glucose-stimulated release of IRI (18). Although this latter study suggests that the inhibition is a direct effect upon pancreatic beta cell function, several other possible mechanisms can be suggested. It is possible that circulatory changes associated with epinephrine may have been responsible for the effects upon insulin levels. In particular a decreased splanchnic or liver blood flow could result in less insulin release into the general circulation without any change in pancreatic response. Studies of hepatic blood flow in man with doses of epinephrine comparable to those used in our study have shown, however, that increased rather than decreased splanchnic blood flow would be expected $(19,20)$. We have estimated splanchnic blood flow with indocyanine green $(21,22)$ in two subjects by using a central injection site and peripheral blood sampling site (23). In both subjects clearance of indicator was unchanged by an epinephrine infusion. With the limitations of this technique, these results are compatible with either no change or an increase in splanchnic blood flow, but not a decrease. Therefore, a reduction in splanchnic flow as an explanation for the effect of epinephrine on blood insulin levels would appear unlikely. Alternative possibilities, which can be summarized briefly, include $a$ ) a direct or indirect effect of epinephrine on the pancreatic microcirculation; $b$ ) production of a metabolically active substance by epinephrine, which in turn decreases pancreatic insulin release; and $c$ ) acceleration of insulin removal that prevents the usual rise in insulin level. None of these other alternatives were investigated and, therefore, further studies in man will be required to evaluate them.

\section{Summary}

Epinephrine, $6 \mu \mathrm{g}$ per minute, was infused into normal subjects. Despite marked hyperglycemia, immunoreactive insulin remained at basal levels until the infusion was stopped. This inhibition of an expected increase in immunoreactive insulin was maintained for up to 7 hours by continuous infusion of epinephrine. Immunoreactive insulin levels were lower than expected when epinephrine was infused simultaneously with glucose, glucagon, and tolbutamide. These data are considered to be consistent with an inhibitory effect of epinephrine upon pancreatic insulin release.

\section{Acknowledgments}

We wish to thank Susan Page, Marlene Zuti, Alison Skeel, and Ron Harbeck for their skillful technical assistance. Dr. Francis C. Wood, Jr., kindly reviewed the manuscript, and Dr. Ruth Kirk assisted with the statistical interpretations.

\section{References}

1. Ellis, S. The metabolic effects of epinephrine and related amines. Pharmacol. Rev. 1956, 8, 485.

2. Yalow, R. S., and S. A. Berson. Immunoassay of endogenous plasma insulin in man. J. clin. Invest. 1960, 39, 1157.

3. Morgan, C. R., and A. Lazarow. Immunoassay of insulin: two antibody system. Plasma insulin levels of normal, subdiabetic and diabetic rats. Diabetes 1963, 12, 115.

4. Mosenthal, H. O., and E. Barry. Criteria for and interpretation of normal glucose tolerance tests. Ann. intern. Med. 1950, 33, 1175. 
5. Samols, E., and D. Bilkus. A comparison of insulin immunoassays. Proc. Soc. exp. Biol. (N. Y.) 1964, 115, 79.

6. Trout, D. L., E. H. Estes, Jr., and S. J. Friedberg. Titration of free fatty acids in plasma: a study of current methods and a new modification. J. Lipid Res. 1960, 1, 199.

7. Wieland, O. Eine enzymatishe Methode zur Bestimmung von Glycerin. Biochem. Z. 1957, 329, 313.

8. Hagen, J. H. The effect of insulin on concentration of plasma glycerol. J. Lipid Res. 1963, 4, 46.

9. Jungas, R. L., and E. G. Ball. Studies on the metabolism of adipose tissue. XII. The effects of insulin and epinephrine on free fatty acid and glycerol production in the presence and absence of glucose. Biochemistry 1963, 2, 383.

10. Mueller, P. S., and W. H. Evans. Responses of plasma glycerol concentrations to epinephrine, norepinephrine, glucose, insulin, and prolonged fasting in man. J. Lab. clin. Med. 1963, 61, 953.

11. Karam, J. H., G. M. Grodsky, F. Ch. Pavlatos, and P. H. Forsham. Critical factors in excessive serum-insulin response to glucose. Obesity in maturity-onset diabetes and growth hormone in acromegaly. Lancet 1965, 1, 286.

12. Roth, J., S. M. Glick, R. S. Yalow, and S. A. Berson. Secretion of human growth hormone: physiologic and experimental modification. Metabolism 1963, 12, 577.

13. Bondy, P. K., and L. R. Cardillo. The effect of glucagon on carbohydrate metabolism in normal human beings. J. clin. Invest. 1956, 35, 494.

14. Havel, R. J., and A. Goldfien. The role of the sympathetic nervous system in the metabolism of free fatty acids. J. Lipid Res. 1959, 1, 102.
15. Shafrir, E., K. E. Sussman, and D. Steinberg. The nature of the epinephrine-induced hyperlipidemia in dogs and its modification by glucose. J. Lipid Res. 1959, 1, 109.

16. Colwell, A. R., and E. M. Bright. The use of constant glucose injections for the study of induced variations in carbohydrate metabolism. IV. Suppression of glucose combustion by continuous prolonged epinephrine administration. Amer. J. Physiol. 1930, 92, 555.

17. Kosaka, K., T. Ide, T. Kuzuya, E. Miki, N. Kuzuya, and S. Okinaka. Insulin-like activity in pancreatic vein blood after glucose loading and epinephrine hyperglycemia. Endocrinology 1964, 75, 9.

18. Coore, H. G., and P. J. Randle. Regulation of insulin secretion with pieces of rabbit pancreas incubated in vitro. Biochem. J. 1964, 93, 66.

19. Bradley, S. E. Liver injury in Transactions of the Fifth Conference, Josiah Macy, Jr., Foundation, F. W. Hoffbauer, Ed. 1946, p. 38.

20. Kibler, R. F., W. J. Taylor, and J. D. Myers. The effect of glucagon on net splanchnic balances of glucose, amino acid nitrogen, urea, ketones, and oxygen in man. J. clin. Invest. 1964, 43, 904.

21. Caesar, J., S. Shaldon, L. Chiandussi, L. Guevara, and S. Sherlock. The use of indocyanine green in the measurement of hepatic blood flow as a test of hepatic function. Clin. Sci. 1961, 21, 43.

22. Wiegand, B. D., S. G. Ketterer, and E. Rapaport. The use of indocyanine green for the evaluation of hepatic function and blood flow in man. Amer. J. dig. Dis. 1960, 5, 427.

23. Porte, D., Jr., A. L. Graber, T. Kuzuya, and R. H. Williams. Unpublished data. 